\title{
Ensemble Design in Nickel Phosphide Catalysts for Alkyne Semi-Hydrogenation
}

\author{
Davide Albani, ${ }^{[\mathrm{a}]}$ Konstantin Karajovic, ${ }^{[\mathrm{b}]}$ Bharath Tata, ${ }^{[\mathrm{a}]}$ Qiang Li, ${ }^{[\mathrm{b}]}$ Sharon Mitchell, ${ }^{[\mathrm{a}]}$ \\ Núria López, ${ }^{*[b]}$ and Javier Pérez-Ramírez ${ }^{*[a]}$
}

\begin{abstract}
Modification of transition metals with $p$-block elements is known to be effective to tune the ensemble characteristics of catalysts for the semi-hydrogenation of alkynes. To further explore this approach, here we prepare two nickel phosphides, namely $\mathrm{Ni}_{2} \mathrm{P}$ and $\mathrm{Ni}_{5} \mathrm{P}_{4}$. Assessment in the semi-hydrogenation of 1-hexyne and 2-methyl-3-butyn-2-ol shows that the phosphides present higher rate and selectivity than unmodified nickel catalysts. While no activity and selectivity differences are displayed in the semi-hydrogenation of 1-hexyne over $\mathrm{Ni}_{2} \mathrm{P}$ and $\mathrm{Ni}_{5} \mathrm{P}_{4}$, in the case of 2-methyl-3-butyn-2-ol a higher rate and
\end{abstract}

\section{Introduction}

The need for sustainable processes in today's society steers research in heterogeneous catalysis towards developing more environmentally friendly and efficient systems. ${ }^{[1,2]}$ Since 1952, the three-phase semi-hydrogenation of alkynes, which is key for the industrial synthesis of drugs, vitamins, fragrances, and agrochemicals, has been conducted over lead-poisoned palladium (5 wt.\%) supported on calcium carbonate (the well-known Lindlar catalyst). ${ }^{[3,4]}$ Severe drawbacks of the state-of-the-art catalyst (i.e., low noble metal utilization, and use of hazardous $\mathrm{Pb}$ ) have prompted a search for alternative materials. ${ }^{[5,6]}$ The replacement of the archetypal catalyst has not been an easy task due to the challenges associated with precisely tailoring the active site to achieve selective performance. On active metals such as $\mathrm{Ni}$ and $\mathrm{Pd}$, to prevent the over-hydrogenation to the alkane, the electronic properties of the catalyst need to be modulated with suitable modifiers, to weaken the adsorption of the desired semihydrogenated product ${ }^{[7-10]}$ so that it can easily detach from the surface improving selectivity. More importantly, oligomerization paths must be suppressed by downsizing the ensemble size to 3 metal atoms, thus avoiding $\mathrm{C}-\mathrm{C}$ couplings which require two

[a] D. Albani, B. Tata, Dr. S. Mitchell, Prof. J. Pérez-Ramírez

Department of Chemistry and Applied Biosciences

Institute for Chemical and Bioengineering

ETH Zurich

Vladimir-Prelog-Weg 1, 8093 Zurich (Switzerland)

E-mail: jpr@chem.ethz.ch

[b] K. Karajovic, Dr. Q. Li, Prof. N. López

The Barcelona Institute of Science and Technology Institute of Chemical Research of Catalonia (ICIQ) Av. Països Catalans 16, 43007 Tarragona (Spain) E-mail: nlopez@iciq.es

Supporting information for this article is available on the WWW under https://doi.org/10.1002/cctc.201801430

- This manuscript is part of the Anniversary Issue in celebration of 10 years of ChemCatChem. lower selectivity to 2-methyl-3-buten-2-ol are observed over $\mathrm{Ni}_{2} \mathrm{P}$. Density functional theory reveals that the hydroxyl group facilitates the reaction, but also increases the barrier for product desorption. Detailed analyses of the ensemble show the potential of phosphorus to create spatially-isolated nickel trimers that surpass the performance of unmodified nickel, but also its limited ability to modulate the electronic properties and related binding energies of organic intermediates, which is key to preventing undesired side reactions.

adjacent alkyne adsorption sites (i.e., comprising at least 5-6 neighboring atoms). ${ }^{[11,12]}$ To reduce the ecological footprint of hydrogenation processes, new materials have been investigated including other metals, alloys and intermetallic compounds, metal oxides, hybrid nanoparticles, supported single atoms, and $p$-block modified noble metals. ${ }^{[6,13]}$ As lately shown by an integrated experimental and theoretical work that classified prominent families of hydrogenation catalysts, the modification of palladiumbased catalysts with sulfur-containing molecules, which yields nanostructured palladium sulfide (i.e., $\mathrm{Pd}_{3} \mathrm{~S}$ and $\mathrm{Pd}_{4} \mathrm{~S}$ ) emerged as one of the most effective ways of tuning the ensemble properties to obtain a robust catalyst. ${ }^{[13,14]}$ To benefit from this design strategy, we have explored if the approach applies to other $p$ block elements.

Transition metal phosphides are an intriguing class of materials that have been applied in different fields from materials science to catalysis. In the latter domain, attention has primarily focused on the activity of $\mathrm{Ni}, \mathrm{Co}, \mathrm{W}$, and Fe phosphides in reactions such as hydrotreating, ${ }^{[15]}$ hydrodenitrization, ${ }^{[16]}$ aminoborane decomposition, ${ }^{[17]}$ and electrochemical hydrogen evolution. ${ }^{[18]}$ Several crystalline phosphide phases exist with different phosphorus-to-metal ratios, $^{[19]}$ potentially offering a material versatility similar to that of sulfides. Thus, it seems possible to optimize the geometric and electronic properties of the ensemble and consequently the catalytic function within this family of compounds. In view of the low cost of nickel (ca. 2000 times cheaper than palladium $)^{[20,21]}$ and of the abundance and hydrogen splitting ability of this metal, nickel phosphides have also attracted interest for alkyne semihydrogenation, although only a few contributions have evaluated their activity. In this respect, Corma and coworkers ${ }^{[2]}$ assessed colloidal nickel phosphides in the semi-hydrogenation of functionalized alkynes, while bulk $\mathrm{Ni}_{x} \mathrm{P}_{y}$ phases were prepared by thermal treatment of hydrotalcite-like compounds containing $\mathrm{Ni}$ and tested in phenylacetylene hydrogenation by Chen et al. ${ }^{[23]}$ These two contributions showed that the well-known unselective 
behavior of bare nickel ${ }^{[9,10]}$ can be modulated by treatment with phosphorus. Similar findings have been recently extrapolated by Anderson et al. ${ }^{[24]}$ to nanostructured palladium phosphide catalysts for gas-phase applications. However, the activity of phosphides could not match that of a nanostructured $\mathrm{Pd}_{4} \mathrm{~S}$ catalyst. Overall, these investigations postulated that the presence of phosphorus on the surface is key in hindering side paths. On the other hand, the origin of the selective performance and the link to ensemble design have not been rationalized at the molecular level.

Herein, we provide fundamental understanding of the performance of nickel phosphide catalysts in alkyne semihydrogenation. This is achieved by combining state-of-the-art Density Functional Theory (DFT), syntheses of bulk nickel phosphides with different stoichiometries $\left(\mathrm{Ni}_{2} \mathrm{P}\right.$ and $\left.\mathrm{Ni}_{5} \mathrm{P}_{4}\right)$, and catalytic tests of linear and functionalized alkynes in continuous-flow mode. In contrast to batch setups commonly employed for laboratory testing, ${ }^{[25]}$ continuous-flow reactors can operate efficiently at steady state and offer key advantages, such as cost reduction, efficient heat transfer, rapid mixing, and small volume usage. ${ }^{[26-28]}$ Overall, an emphasis is placed on the role of the ensemble properties on the complex reaction network, revealing the limitations of phosphorus as an effective electronic modifier.

\section{Results and Discussion}

\section{Catalysts Preparation and Characterization}

Nickel phosphides are generally prepared by reacting the pure elements (i.e., $\mathrm{Ni}$ and yellow or red phosphorus) or alternatively using nickel salts in combination with phosphorus-containing compounds such as, phosphines and phosphonic acid. ${ }^{[29]}$ Many works have investigated the use of yellow phosphorus, which enables precise control over the final stoichiometry, but its highly pyrophoric behavior and the need for water-free conditions make it unattractive. ${ }^{[16]}$ In this contribution we synthesized two of the most robust $\mathrm{Ni}_{x} \mathrm{P}_{y}$ structures: $\mathrm{Ni}_{5} \mathrm{P}_{4}$ and $\mathrm{Ni}_{2} \mathrm{P}$. The former can be readily prepared from more stable red phosphorus, by treatment with metallic nickel powder under an inert atmosphere at $773 \mathrm{~K}$, while it is also straightforward to isolate the latter by the reaction of nickel chloride hexahydrate and sodium hypophosphite at $573 \mathrm{~K}^{[30]}$

Following these approaches, two nickel phosphides with different stoichiometry were obtained. X-ray diffraction analyses confirmed the presence of a single crystalline phase corresponding to the hexagonal structure of $\mathrm{Ni}_{2} \mathrm{P}$ or $\mathrm{Ni}_{5} \mathrm{P}_{4}$, respectively (Figure 1a). Also, $\mathrm{Ni}_{5} \mathrm{P}_{4}$ does not display any reflections from the nickel powder precursor. The experimentally determined lattice parameters agree well with the calculated values (Table S1). In comparison, Ni presents the typical diffractogram of metallic nickel, while the commercial $\mathrm{Ni} / \mathrm{SiO}_{2}-\mathrm{Al}_{2} \mathrm{O}_{3}$ displays reflections arising from both metallic and oxidic nickel phases. Consistent with the expected stoichiometries, assessment of the bulk composition by $\mathrm{X}$-ray fluorescence (XRF) evidenced an atomic Ni/P ratio of $2\left(\mathrm{Ni}_{2} \mathrm{P}\right)$ or $1.2\left(\mathrm{Ni}_{5} \mathrm{P}_{4}\right)$, and excluded the presence of trace impurities. Analysis by $\mathrm{N}_{2}$ physisorption
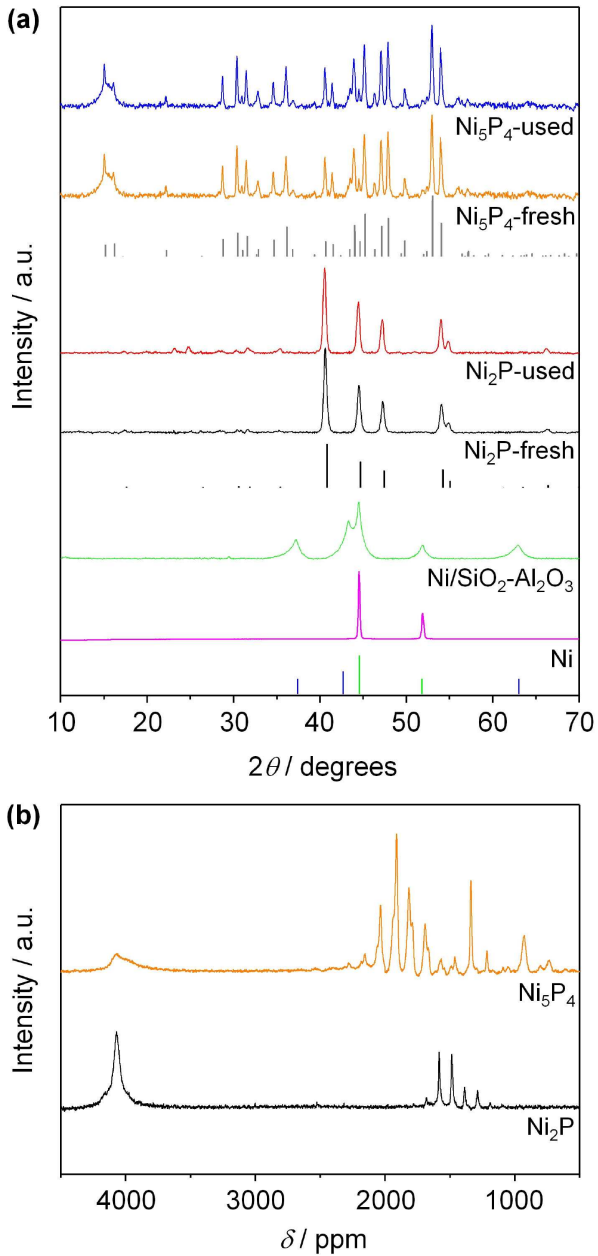

Figure 1. (a) X-ray diffraction patterns and (b) ${ }^{31} \mathrm{P}$ magic angle spinning nuclear magnetic resonance spectra of the catalysts. Vertical lines below the diffractograms in (a) show the reference patterns of $\mathrm{Ni}_{2} \mathrm{P}$ (PDF-Number 98005-2967), $\mathrm{Ni}_{5} \mathrm{P}_{4}$ (PDF-Number 98-004-8850), Ni (green, PDF-Number 98-0060941), and $\mathrm{Ni}_{15} \mathrm{O}_{16}$ (blue, PDF-Number 98-008-8918).

confirmed the nonporous nature of these phosphides and of the nickel precursor, which display Brunauer-Emmett-Teller (BET) surface areas lower than $1 \mathrm{~m}^{2} \mathrm{~g}^{-1}$, while the commercial catalyst featured a high surface area (i.e., $190 \mathrm{~m}^{2} \mathrm{~g}^{-1}$ ) due to the high porosity of the silica-alumina support. Solid state magic angle spinning nuclear magnetic resonance spectroscopy (MASNMR) was applied to further probe the atomic structure. The analysis focused on ${ }^{31} \mathrm{P}$, considering the high sensitivity and abundance of this nucleus (Figure $1 \mathrm{~b}$ ). The spectra agree well with previously reported data. ${ }^{[31,32]}$ In particular, the high chemical shifts observed are expected due to the metallic character of the two phases, which is responsible for the socalled Knight shift (Table 1). $\mathrm{Ni}_{2} \mathrm{P}$ displays two inequivalent phosphorus sites with very different chemical shifts, which are assigned to a phosphorus atom shared by two $\mathrm{NiP}_{4}$ tetrahedral and one at the common edge of a $\mathrm{NiP}_{4}$ tetrahedral and a $\mathrm{NiP}_{5}$ pyramid, respectively. On the other hand, the case of $\mathrm{Ni}_{5} \mathrm{P}_{4}$ is more complex because, from inspection of the spectra, 5 types of inequivalent $P$ sites are identified in the region 800- 
Table 1. $\mathrm{Ni}-\mathrm{Ni}, \mathrm{Ni}-\mathrm{P}$, and $\mathrm{P}-\mathrm{P}$ bond distances on the catalyst surfaces.

\begin{tabular}{|c|c|c|c|c|}
\hline Bond & $\mathrm{Ni}(111)$ & $\mathrm{Ni}_{3} \mathrm{P}(0001)$ & $\mathrm{Ni}_{3} \mathrm{P}_{2}(0001)$ & $\mathrm{Ni}_{4} \mathrm{P}_{3}(0001)$ \\
\hline $\mathrm{Ni}-\mathrm{Ni}[\AA ̊]$ & 2.492 & 3.177 & 2.716 & $2.413 ; 2.619$ \\
\hline $\mathrm{Ni}-\mathrm{P}[\AA \AA]$ & - & 5.876 & 3.393 & $3.088 ; 3.711$ \\
\hline 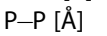 & - & $2.268 ; 3.652$ & 2.188 & $2.322 ; 3.174$ \\
\hline
\end{tabular}

$2200 \mathrm{ppm}$ at 1910,1816,1340, 930, and $720 \mathrm{ppm}$ with the corresponding sidebands. The five sites arise due to the specific atomic structure of $\mathrm{Ni}_{5} \mathrm{P}_{4}$ in which $\mathrm{P}$ atoms are surrounded by different numbers of nearest neighbor $\mathrm{Ni}$ atoms. ${ }^{[33]}$ The appearance of distinct bands associated with each $\mathrm{P}$ position may vary depending on both the extent of structural disorder in the phase and on the measurement conditions. ${ }^{[32]}$ The latter are particularly critical due to the metallic character of nickel phosphides that limits the spinning speed that can be applied and can produce spurious signals related to temperature effects. Also, the origin of the band at 4000 ppm is unclear.

\section{Geometric Properties of $\mathrm{Ni}_{x} \mathrm{P}_{y}$ Ensembles}

A selective semi-hydrogenation catalyst requires spatially-isolated ensembles to avoid the occurrence of $\mathrm{C}-\mathrm{C}$ coupling, which leads to oligomerization. This is assessed by identifying the distribution of nickel and phosphorus on the surface and associated ensemble motifs. Upon inspection of $\mathrm{Ni}(111)$ and the $(2 \times 2)$ supercells of two terminations of $\mathrm{Ni}_{2} \mathrm{P}\left(\mathrm{Ni}_{3} \mathrm{P}(0001)\right.$ and $\left.\mathrm{Ni}_{3} \mathrm{P}_{2}(0001)\right)$, and the lowest energy termination of $\mathrm{Ni}_{5} \mathrm{P}_{4}$ $\left(\mathrm{Ni}_{4} \mathrm{P}_{3}(0001)\right)$ (Figure 2), it is possible to identify a pattern of trimeric ensembles in all cases. In particular, we can determine that the distribution and relative organization of fcc (green) and hcp (yellow) sites change from the $\mathrm{Ni}(111)$ to $\mathrm{Ni}_{4} \mathrm{P}_{3}(0001)$ surface depending on the surface concentration of phosphorus. For example, while the green ensembles, which are arranged in larger triangular motifs, on $\mathrm{Ni}_{3} \mathrm{P}(0001)$ are interrupted by one phosphorus, on $\mathrm{Ni}_{3} \mathrm{P}_{2}(0001)$ and $\mathrm{Ni}_{4} \mathrm{P}_{3}(0001)$ the number of phosphorus atoms between the nickel ensembles increases. This implies a higher degree of separation and lower density of $\mathrm{Ni}_{3}$ ensembles on the surface compared to the palladium ensembles on $\mathrm{Pd}_{3} \mathrm{~S}_{1}{ }^{[13]}$ pointing out the high efficiency of phosphorus in imparting geometric modifications.

To understand the phosphorus-rich nature of the surfaces, the segregation energy, $E_{\text {seg, }}$ which is a robust parameter for evaluating the tendency of bulk $\mathrm{P}$ and/or $\mathrm{Ni}$ atoms to migrate to the surface, and the island formation energy, $E_{\text {isl, }}$ which is used to describe the possibility of forming surface homoatomic domains, have been calculated (Tables S2 and S3). In all cases phosphorus atoms are identified to be prone to migrate to the surface, while nickel prefers to move to the bulk. However, as liquid phase applications at mild temperatures are conducted in the current study, the extent of diffusion of phosphorus atoms towards the surface is expected to be minimal.

\section{Adsorption Properties of $\mathrm{Ni}_{x} \mathrm{P}_{y}$ Ensembles}

Evaluation of the adsorption energies of $\mathrm{C}_{2} \mathrm{H}_{2}, \mathrm{C}_{2} \mathrm{H}_{4}$, and $\mathrm{C}_{2} \mathrm{H}_{6}$ on the investigated surfaces (Figures $\mathrm{S} 1-\mathrm{S} 4$ ) provides a means of determining the impact of phosphorus on the electronic properties of the ensembles. The values can be compared with other prominent classes of hydrogenation catalysts to derive a hierarchy of the effectiveness of different approaches to optimize ensemble design. The adsorption energy of $\mathrm{C}_{2} \mathrm{H}_{2}$ is one of the main activity descriptors for alkyne semi-hydrogenation catalysts and needs to be exothermic. ${ }^{[20]}$ While $\mathrm{C}_{2} \mathrm{H}_{2}$ binds strongly to all surfaces, the adsorption geometry of the activated acetylenic fragment changes as a function of the nickel ensemble and participating phosphorus atoms. On $\mathrm{Ni}$ (111), $\mathrm{C}_{2} \mathrm{H}_{2}$ can bind either to a site containing four $\mathrm{Ni}$ atoms with the $\mathrm{C}-\mathrm{C}$ bond sitting perpendicular $\left(E_{\mathrm{ads}}=-2.90 \mathrm{eV}\right)$ or above the $\mathrm{Ni}_{3}$ site with the two $\mathrm{C}$ atoms on two $\mathrm{Ni}-\mathrm{Ni}$ bridge positions, $\left(E_{\text {ads }}=-2.50 \mathrm{eV}\right)$ (Figure $\left.\mathrm{S} 1\right)$. On $\mathrm{Ni}_{3} \mathrm{P}(0001)$, two ethylene-like structures, $\mathrm{P}-\mathrm{CH}-\mathrm{CH}-\mathrm{Ni}$, and $\mathrm{Ni}-\mathrm{CH}-\mathrm{CH}-\mathrm{Ni}$, are identified with energies of -2.07 and $-1.66 \mathrm{eV}$, respectively. Similarly, on $\mathrm{Ni}_{3} \mathrm{P}_{2}(0001), \mathrm{P}-\mathrm{CH}-\mathrm{CH}-\mathrm{P}$ and $\mathrm{Ni}-\mathrm{CH}-\mathrm{CH}-\mathrm{Ni}$ can be distinguished with $E_{\text {ads }}$ of -2.23 and $-2.47 \mathrm{eV}$, respectively. On $\mathrm{Ni}_{4} \mathrm{P}_{3}(0001)$, the most stable structure is $\mathrm{P}-\mathrm{CH}-\mathrm{CH}-\mathrm{P}$ with the two $C$ atoms bound to $\mathrm{P}$ atoms $\left(E_{\mathrm{ads}}=-3.07 \mathrm{eV}\right)$. In contrast to other $p$-block-doped metal surfaces, the binding of the alkyne to phosphorus atoms is much stronger than at any other possible coordination sites on $\mathrm{Ni}_{x} \mathrm{P}_{y}$.

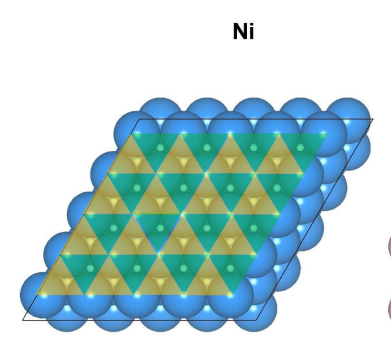

$\mathrm{Ni}(111)$

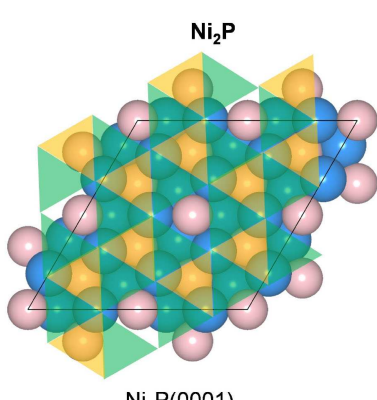

$\mathrm{Ni}_{3} \mathrm{P}(0001)$

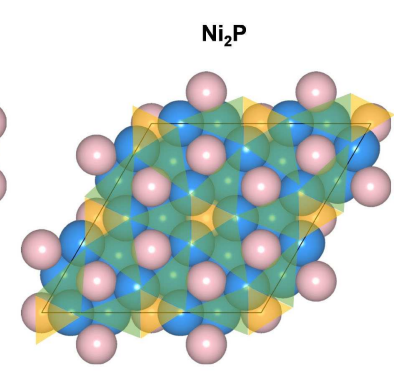

$\mathrm{Ni}_{3} \mathrm{P}_{2}(0001)$

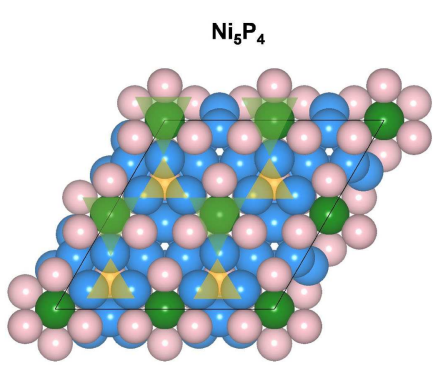

$\mathrm{Ni}_{4} \mathrm{P}_{3}(0001)$

Figure 2. Top view of the $\mathrm{Ni}(111), \mathrm{Ni}_{2} \mathrm{P}\left(\mathrm{Ni}_{3} \mathrm{P}(0001)\right.$ and $\mathrm{Ni}_{3} \mathrm{P}_{2}(0001)$ terminations) and $\mathrm{Ni}_{5} \mathrm{P}_{4}\left(\mathrm{Ni}_{4} \mathrm{P}_{3}(0001)\right.$ termination) surfaces. Color code: $\mathrm{Ni}($ blue and green), $\mathrm{P}$ (pink). Triangles highlight the nickel atoms forming surface ensembles. $\mathrm{Ni}_{4} \mathrm{P}_{3}(0001)$ displays two inequivalent $\mathrm{Ni}$ colored in blue and green. 
To obtain a high selectivity to the desired product, it is important that the intermediate alkene displays a thermoneutral or endothermic adsorption energy, so that it can easily detach from the surface, suppressing over-hydrogenation. $\mathrm{C}_{2} \mathrm{H}_{4}$ binds to $\mathrm{Ni}(111)$ via one carbon to the nickel top site and the other carbon to the $\mathrm{Ni}-\mathrm{Ni}$ bridge site ${ }^{[9]}$ with a binding energy of $-1.14 \mathrm{eV}$ (Figure S1). This binding geometry is not affected by the surface composition since the adsorption energy on $\mathrm{Ni}_{3} \mathrm{P}$ (0001) and $\mathrm{Ni}_{3} \mathrm{P}_{2}(0001)$ is -1.13 , and $-1.26 \mathrm{eV}$, respectively (Figures S2 and S3). On $\mathrm{Ni}_{4} \mathrm{P}_{3}(0001)$, the adsorption of $\mathrm{C}_{2} \mathrm{H}_{4}$ to a phosphorus site, forming $\mathrm{P}-\mathrm{CH}_{2}-\mathrm{CH}_{2}-\mathrm{P}$, is even stronger $\left(E_{\mathrm{ads}}=\right.$ $-2.23 \mathrm{eV}$ ) and more stable than on the $\mathrm{Ni}_{3}$ site of the same surface $\left(E_{\mathrm{ads}}=-0.98 \mathrm{eV}\right)$. This shows that having trimeric $\mathrm{Ni}$ ensembles spaced by phosphorus atoms does not necessarily poison nickel, but it provides new P-containing sites on the surfaces with stronger adsorption features.

\section{Hydrogenation of Alkynes}

The nickel phosphide catalysts were evaluated in the continuous-flow three-phase semi-hydrogenation of 1-hexyne, a substrate widely studied to probe the selective character of alkyne hydrogenation catalysts, and benchmarked against the nickel precursor. Figure 3a maps the influence of the reaction temperature and pressure on the rate and selectivity to 1-hexene. While both $\mathrm{Ni}_{2} \mathrm{P}$ and $\mathrm{Ni}_{5} \mathrm{P}_{4}$ display very similar performance under every condition evaluated, for instance, at $303 \mathrm{~K}$ and 10 bar the rate of 1 -hexyne conversion is 1.3 and $1.4 \mathrm{~h}^{-1}$, on $\mathrm{Ni}_{2} \mathrm{P}$ and $\mathrm{Ni}_{5} \mathrm{P}_{4}$, respectively, $\mathrm{Ni}$ present much lower reaction rate, $0.4 \mathrm{~h}^{-1}$. Remarkably, nickel phosphides are almost fully selective (higher than 95\%) to the desired alkene even at high pressure $(P=20 \mathrm{bar})$ and temperature $(T=343 \mathrm{~K})$, while $\mathrm{Ni}$ displays $c a .70 \%$ selectivity at a much lower conversion level (Figure S5). This points to the robustness of nickel phosphides to the formation of $\beta$-hydrides, which bare nickel is known to suffer from, and to the beneficial effect of introducing phosphorus into the nickel lattice to increase both the activity and the selectivity. To assess the selectivity patterns of a Nibased catalyst at higher conversion levels, a commercial $60 \mathrm{wt} . \% \mathrm{Ni} / \mathrm{SiO}_{2}-\mathrm{Al}_{2} \mathrm{O}_{3}$ catalyst was evaluated in 1-hexyne hydrogenation. At $343 \mathrm{~K}$ and 20 bar the rate of 1 -hexyne conversion on $\mathrm{Ni} / \mathrm{SiO}_{2}-\mathrm{Al}_{2} \mathrm{O}_{3}$ is $3.5 \mathrm{~h}^{-1}$ and the selectivity to 1hexene of $18 \%$, with $n$-hexane as the major side product and traces of isomers of the double bond (ca. $5 \%$ ). These results indicate that supported nickel-based catalyst can match and surpass the activity of bulk nickel phosphides, but at the expenses of a very low selectivity to the semi-hydrogenated product.

The catalysts were additionally evaluated in the continuousflow three-phase semi-hydrogenation of 2-methyl-3-butyn-2-ol at various temperatures and pressures. Conversely from the case of 1-hexyne, where $\mathrm{Ni}_{2} \mathrm{P}$ and $\mathrm{Ni}_{5} \mathrm{P}_{4}$ display similar activity profiles, significant differences are observed in the hydrogenation of the alkynol (Figure $3 \mathrm{~b}$ ). In particular, at $303 \mathrm{~K}$ and 5 bar the rate of 2-methyl-3-butyn-2-ol conversion is 1.6 and $1.1 \mathrm{~h}^{-1}$, while the selectivity to 2-methyl-3-buten-2-ol is 92 and
$90 \%$ on $\mathrm{Ni}_{2} \mathrm{P}$ and $\mathrm{Ni}_{5} \mathrm{P}_{4}$, respectively. These results point to the higher activity of $\mathrm{Ni}_{2} \mathrm{P}$ than $\mathrm{Ni}_{5} \mathrm{P}_{4}$ when compared under the same conditions, and call for a molecular-level understanding of this behavior. In line with the observations for 1-hexyne, $\mathrm{Ni}$ and $\mathrm{Ni} / \mathrm{SiO}_{2}-\mathrm{Al}_{2} \mathrm{O}_{3}$ exhibit lower and similar reaction rates to $\mathrm{Ni}_{x} \mathrm{P}_{y}$, respectively. Also, at $343 \mathrm{~K}$ and 20 bar, the selectivity to 1hexene on $\mathrm{Ni}$ and $\mathrm{Ni} / \mathrm{SiO}_{2}-\mathrm{Al}_{2} \mathrm{O}_{3}$ is $60 \%$ and $10 \%$, respectively.

To verify the robustness on stream, a long-term test was conducted over the catalysts. As shown in Figure 4, both $\mathrm{Ni}_{2} \mathrm{P}$ and $\mathrm{Ni}_{5} \mathrm{P}_{4}$ displayed an induction period of $2 \mathrm{~h}$, likely due to the reduction of the oxidic layer covering the surface, ${ }^{[16]}$ before reaching stable performance for $28 \mathrm{~h}$ on stream, confirming the suitability of these systems for continuous-flow applications. Analysis of the used catalysts by X-ray diffraction and X-ray fluorescence spectrometry confirmed the preservation of the crystalline structure and the absence of leaching of either $\mathrm{Ni}$ or P.

The recent kinetic study over palladium sulfides evidenced the role of the $p$-block element (i.e., sulfur) in stabilizing the activated $\mathrm{H}$ atoms, imparting a bifunctional mechanism that originates higher activity than unmodified palladium nanoparticles, where $\mathrm{H}_{2}$ and the alkyne compete for the same site. ${ }^{[13]}$ Prompted by these observations, the mechanism was explored by conducting kinetic tests to determine the reaction order with respect to hydrogen and the alkyne over $\mathrm{Ni}_{2} \mathrm{P}, \mathrm{Ni}_{5} \mathrm{P}_{4}$, and $\mathrm{Ni} / \mathrm{SiO}_{2}-\mathrm{Al}_{2} \mathrm{O}_{3}$. In line with previous investigations, ${ }^{[13]}$ the order with respect to molecular hydrogen is positive (ca. 1.2) in all cases, while the order to the alkyne is close to 0 for nickel phosphide $\left(-0.04\right.$ and -0.20 for $\mathrm{Ni}_{2} \mathrm{P}$ and $\mathrm{Ni}_{5} \mathrm{P}_{4}$, respectively, Figure $\mathrm{S} 6$ ), and -1 over $\mathrm{Ni} / \mathrm{SiO}_{2}-\mathrm{Al}_{2} \mathrm{O}_{3}$, suggesting in the latter situation a competition between the alkyne and hydrogen on the surface of the unmodified nickel nanoparticles. Also, this indicates a role of the heteroatom in the reaction mechanism as now a two-site model is required to describe the kinetic behavior.

It is noteworthy that in comparison with the nickel phosphides, a nanostructured $\mathrm{Pd}_{3} \mathrm{~S}$ catalyst, the highest-performing Pdbased catalyst identified to date, displayed a two orders of magnitude higher reaction rate under every condition evaluated. This indicates that phosphorus is not able to sufficiently promote the performance of nickel to match that of palladium.

\section{Reaction Mechanism}

To understand the structure sensitive or insensitive activity profile as a function of the substrate, molecular solvation corrected reaction profiles for the hydrogenation of $\mathrm{C}_{2} \mathrm{H}_{2}$ to $\mathrm{C}_{2} \mathrm{H}_{6}$, comprising four hydrogenation steps $\left(\mathrm{CHCH}^{*}+4 \mathrm{H}^{*} \rightarrow \mathrm{CHCH}_{2}{ }^{*}+3 \mathrm{H}^{*} \rightarrow\right.$ $\mathrm{CH}_{2} \mathrm{CH}_{2}{ }^{*}+2 \mathrm{H}^{*} \rightarrow \mathrm{CH}_{2} \mathrm{CH}_{3}{ }^{*}+\mathrm{H}^{*} \rightarrow \mathrm{CH}_{3} \mathrm{CH}_{3}{ }^{*}$ ), were computed (Figure 5). On $\mathrm{Ni}(111)$, the reaction barriers (energies) are $1.02(0.61)$, 0.60 (-0.02), 0.55 (0.39), $1.17(-0.07)$ eV. For $\mathrm{Ni}_{2} \mathrm{P}, \mathrm{Ni}_{3} \mathrm{P}_{2}(0001)$ was selected to investigate the reaction due to its higher stability. ${ }^{[34]}$ The corresponding values are: $0.93(0.20), 1.00(-0.04), 1.05(0.49)$, and $1.09(-0.05) \mathrm{eV}$. The situation on $\mathrm{Ni}_{3} \mathrm{P}_{4}(0001)$ is slightly different. Since $\mathrm{C}_{2} \mathrm{H}_{2}$ can be bound with two different adsorption structures, $\mathrm{P}-\mathrm{CH}-\mathrm{CH}-\mathrm{P}$ and $\mathrm{P}-\mathrm{CH}-\mathrm{CH}-\mathrm{Ni}$ (vide supra), with the former showing stronger adsorption that might potentially poison 
(a)<smiles>C#CCCCC[CH-]C=CCCCCC</smiles>
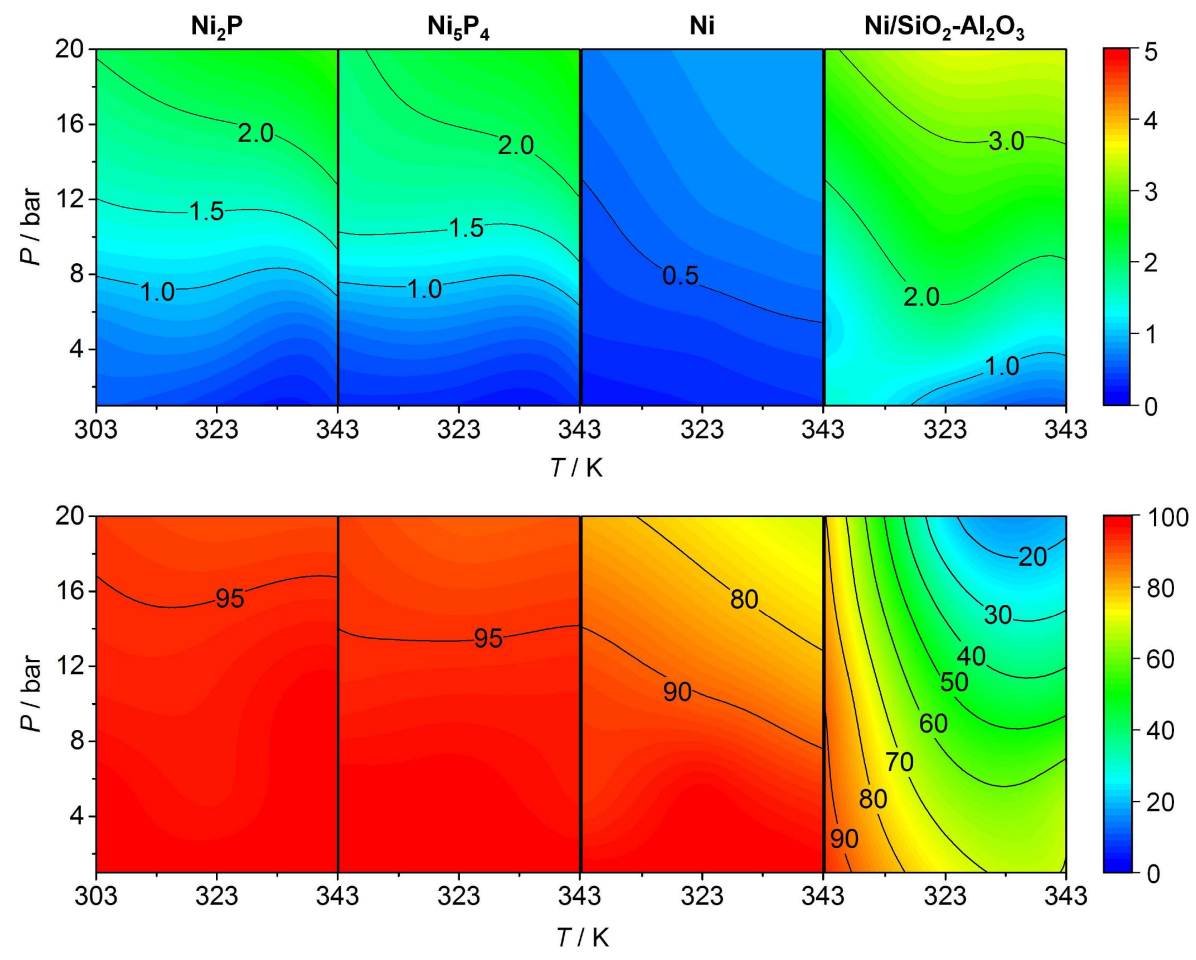

(b)
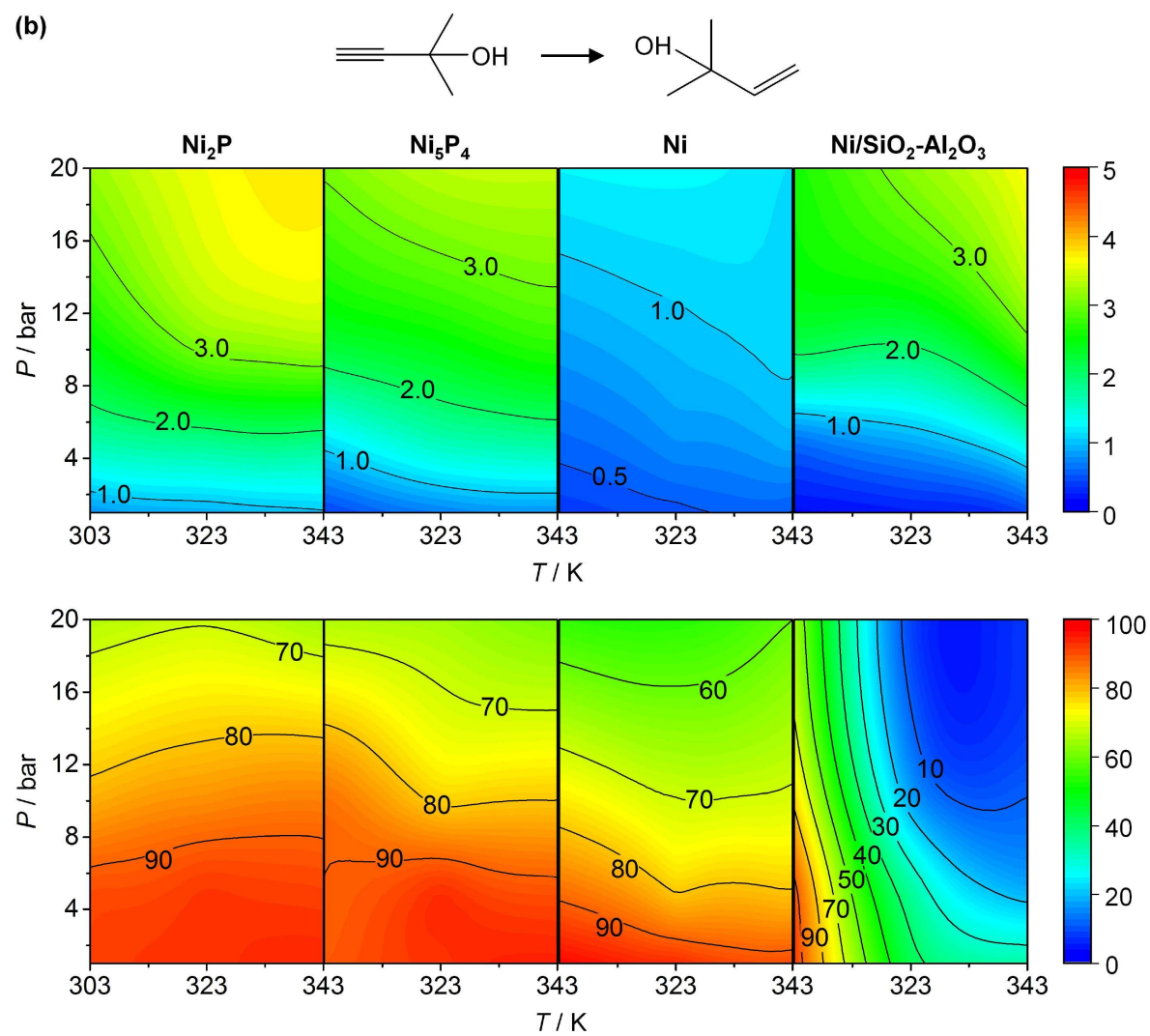

Figure 3. Reaction rate (top row, in $\mathrm{mol}_{\mathrm{alkyne}} \mathrm{mol}_{\mathrm{Ni}}{ }^{-1} \mathrm{~h}^{-1}$ ) and selectivity (bottom row, in \%) in the hydrogenation of (a) 1-hexyne to 1-hexene and (b) 2-methyl3-butyn-2-ol to 2-methyl-3-buten-2-ol over the catalyst as a function of the temperature and pressure. Conditions: $W_{\text {cat }}=0.2 \mathrm{~g}, F_{\mathrm{L}}($ alkyne + toluene) $=0.5 \mathrm{~cm}^{3} \mathrm{~min}^{-1}, F_{\mathrm{G}}\left(\mathrm{H}_{2}\right)=48 \mathrm{~cm}^{3} \mathrm{~min}^{-1}$. 


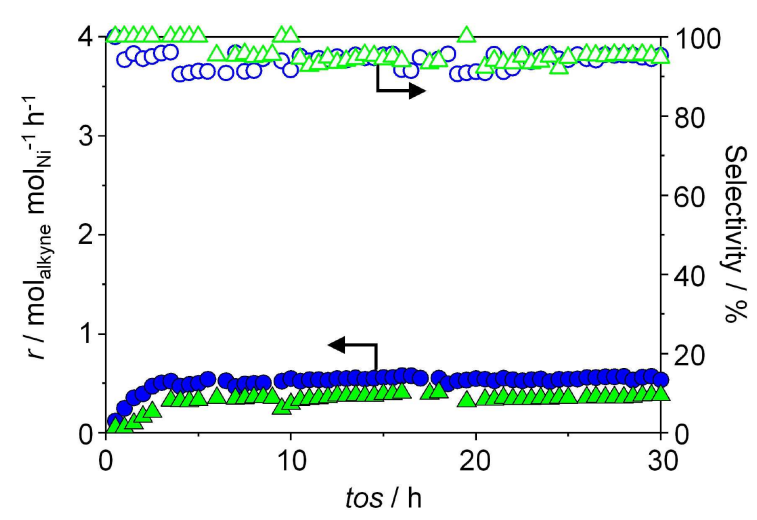

Figure 4. Reaction rate (solid symbols) and selectivity (open symbols) to 2methyl-3-buten-2-ol over $\mathrm{Ni}_{2} \mathrm{P}$ (blue) and $\mathrm{Ni}_{5} \mathrm{P}_{4}$ (green) versus time-on-stream in the hydrogenation of 2-methyl-3-butyn-2-ol to 2-methyl-3-buten-2-ol. Conditions: $W_{\text {cat }}=0.2 \mathrm{~g}, P=1 \mathrm{bar}, T=303 \mathrm{~K}, F_{\mathrm{L}}$ (alkyne + toluene) $=0.5 \mathrm{~cm}^{3} \mathrm{~min}^{-1}, F_{\mathrm{G}}\left(\mathrm{H}_{2}\right)=48 \mathrm{~cm}^{3} \mathrm{~min}^{-1}$

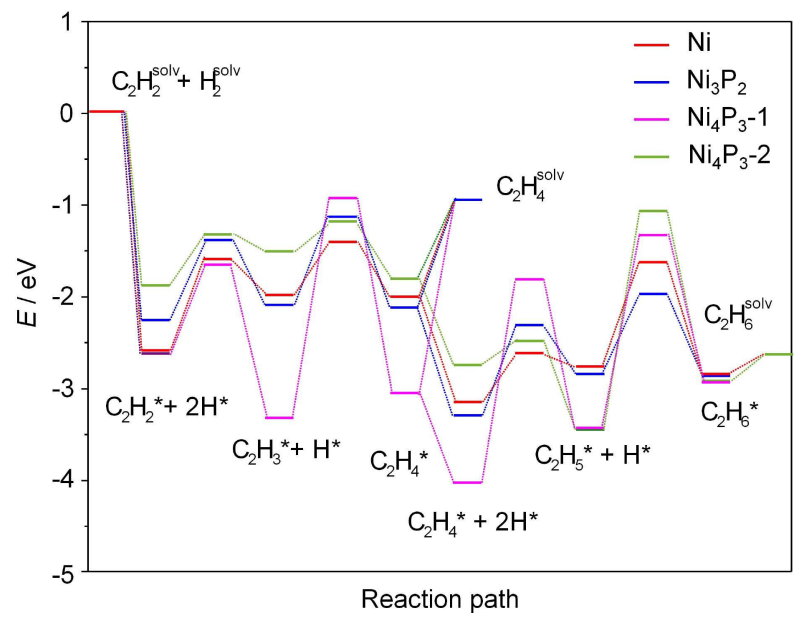

Figure 5. Energy profiles for the hydrogenation of acetylene on the $\mathrm{Ni}(111)$, $\mathrm{Ni}_{3} \mathrm{P}(0001), \mathrm{Ni}_{3} \mathrm{P}_{2}(0001)$ and $\mathrm{Ni}_{4} \mathrm{P}_{3}(0001)$ surfaces. $\mathrm{Ni}_{4} \mathrm{P}_{3}-1$ and $\mathrm{Ni}_{4} \mathrm{P}_{3}-2$ indicate that the profiles consider two different adsorption configurations of the acetylene molecule, forming $\mathrm{P}-\mathrm{CH}-\mathrm{CH}-\mathrm{P}$ and $\mathrm{P}-\mathrm{CH}-\mathrm{CH}-\mathrm{Ni}$ intermediates, respectively.

the surface, both were taken as starting points to investigate the reaction. From $\mathrm{P}-\mathrm{CH}-\mathrm{CH}-\mathrm{P}$ the energies of the reaction profile are $\left(\mathrm{Ni}_{4} \mathrm{P}_{3}-1\right.$ in Figure 5) are $0.98(-0.75), 2.50(0.29), 1.40(-0.33), 2.20$ (0.64) eV; whereas considering $\mathrm{Ni}-\mathrm{CH}-\mathrm{CH}-\mathrm{P}$ they are $0.54(0.37)$, $0.33(-0.32), 0.27(-0.72), 2.46(0.56) \mathrm{eV}\left(\mathrm{Ni}_{4} \mathrm{P}_{3}-2\right.$ in Figure 5). From analysis of the barriers for the hydrogenation steps, it can be inferred that breaking the $\mathrm{P}-\mathrm{C}$ bond is energetically demanding and thus the adsorption of acetylene on the P-containing sites would not lead to a reaction.

The $\mathrm{C}_{2} \mathrm{H}_{4}$ desorption barriers on $\mathrm{Ni}(111), \mathrm{Ni}_{3} \mathrm{P}_{2}(0001)$, and $\mathrm{Ni}_{4} \mathrm{P}_{3}(0001)$ are $1.14,1.26,2.23\left(\mathrm{P}-\mathrm{CH}_{2}-\mathrm{CH}_{2}-\mathrm{P}\right)$ and $1.04 \mathrm{eV}$ $\left(\mathrm{P}-\mathrm{CH}_{2}-\mathrm{CH}_{2}-\mathrm{Ni}\right.$ ), which are lower (once entropy contributions are included) or comparable to the corresponding highest overhydrogenation barriers to $\mathrm{C}_{2} \mathrm{H}_{6}$ of $1.17,1.09,2.20$, and $2.46 \mathrm{eV}$, respectively. This clarifies why the reaction is selective to the alkene. The above energies correspond to gas-phase models, and thus are referred to as gas-phase $\mathrm{C}_{2} \mathrm{H}_{2}, \mathrm{H}_{2}$, and clean surfaces. To describe the effect of the solvent, ${ }^{[35]}$ we calculated the adsorption of toluene on all surfaces $(-1.17,-1.35,-1.30$ and $-1.47 \mathrm{eV}$, on $\mathrm{Ni}(111), \quad \mathrm{Ni}_{3} \mathrm{P}(0001), \mathrm{Ni}_{3} \mathrm{P}_{2}(0001)$, and $\mathrm{Ni}_{4} \mathrm{P}_{3}(0001)$, respectively). The very negative value indicates that toluene displaces $\mathrm{C}_{2} \mathrm{H}_{4}$ from the surface.

The higher rate of 2-methyl-3-butyn-2-ol conversion experimentally observed over $\mathrm{Ni}_{2} \mathrm{P}$ (Figure 3 ) and the similar activity for 1-hexyne hydrogenation are rationalized based on the computed reaction profiles. The hydrogenation of 1-hexyne can be directly mapped to the profile for $\mathrm{C}_{2} \mathrm{H}_{2}$ as they are both linear and unfunctionalized alkynes. The step with the highest potential energy in the reaction profile (Figure 5), $\mathrm{CHCH}_{2}{ }^{*}+$ $\mathrm{H}^{*} \rightarrow \mathrm{CH}_{2} \mathrm{CH}_{2}{ }^{*}$, on $\mathrm{Ni}_{3} \mathrm{P}_{2}(0001)$ and $\mathrm{Ni}_{4} \mathrm{P}_{3}(0001)$ differs only by $0.06 \mathrm{eV}$. The minor differences in the energy landscape for the reaction on both catalysts shows again the negligible impact on the overall performance of nickel phosphides by varying the compositional Ni/P ratios between 2 and 1.2.

A different picture is observed in the hydrogenation of 2methyl-3-butyn-2-ol where the potential energy features a $0.25 \mathrm{eV}$ higher barrier on $\mathrm{Ni}_{4} \mathrm{P}_{3}(0001)$ compared to $\mathrm{Ni}_{3} \mathrm{P}_{2}(0001)$ (Figure S7), which facilitates the reaction path on $\mathrm{Ni}_{2} \mathrm{P}$ over $\mathrm{Ni}_{5} \mathrm{P}_{4}$. This difference in reaction barrier can be traced back to the specific interactions between the alkyne and the surface, which changes the reaction profile. Also, the binding between the hydroxyl group of the alkynol and the surface increases the product desorption barrier, which enhances the likelihood of competitive over-hydrogenation, explaining why the selectivity levels to the alkene decrease in the hydrogenation of 2-methyl3-butyn-2-ol (70\%) compared to 1-hexyne (95\%) (Figures S7 and S8).

To gain further insight into the highly selective character of the nickel phosphide catalysts, isomerization paths were investigated for 1-hexyne. These processes are one of the main cause of poor selectivity in hydrogenation reactions and require the formation and cleavage of $\mathrm{C}-\mathrm{H}$ bonds in different carbon positions. On the unmodified $\mathrm{Ni}$ surface the dehydrogenation step was found to feature similar barriers and thus compete with the hydrogenation step, while on $\mathrm{Ni}_{x} \mathrm{P}_{y}$ the hydrogenation requires lower barriers (Table 54 ).

The higher activity in the hydrogenation of 2-methyl-3butyn-2-ol on $\mathrm{Ni}_{2} \mathrm{P}$ and high and low selectivity to 1-hexene and of 2-methyl-3-buten-2-ol on both catalyst not only indicates that the catalyst performance is sensitive to the substrate, but also the lack of an impact of the $\mathrm{Ni} / \mathrm{P}$ ratio on the selectivity patterns within the range investigated. Phosphorus acts effectively in forming $\mathrm{Ni}_{3}$ triangular ensembles, but its modification of the electronic properties is limited. Optimal semi-hydrogenation performance is known to depend on a complex interplay of parameters, comprising the binding of the reactants and intermediates, and the $d$-band shift. By evaluating the adsorption energies, $\mathrm{C}_{2} \mathrm{H}_{2}$ and $\mathrm{C}_{2} \mathrm{H}_{4}$ are found to be $c a .1 \mathrm{eV}$ more strongly bound to $\mathrm{Ni}_{x} \mathrm{P}_{y}$ than to $\mathrm{Pd}_{3} \mathrm{~S}$ (Table S5). Comparatively, the adsorption of $\mathrm{C}_{2} \mathrm{H}_{4}$ on $\mathrm{Ni}_{3}$ undergoes only minor variation, $0.25 \mathrm{eV}$, with respect to unmodified $\mathrm{Ni}(111)$ (Figure 6 and Figure S9), while a significant decrease is observed from $\mathrm{Pd}$ (111) to $\mathrm{Pd}_{3} \mathrm{~S}(202)$, from -0.85 to $-0.22 \mathrm{eV}$, respectively. This is 


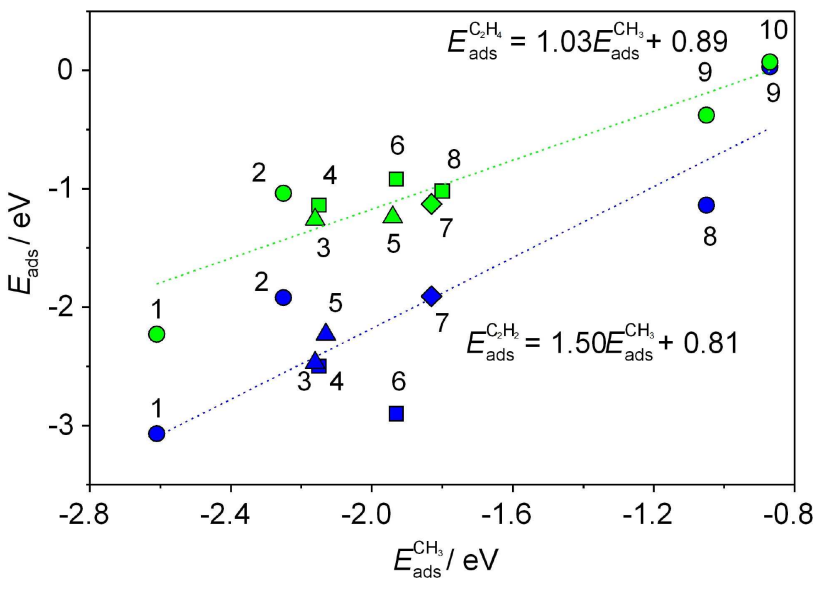

Figure 6. Scaling relationship for the adsorption energy of $\mathrm{C}_{2} \mathrm{H}_{2}$ (blue) and $\mathrm{C}_{2} \mathrm{H}_{4}$ (green) as a function of the adsorption energy of the methyl group on $\mathrm{Ni}(111)$ (squares), $\mathrm{Ni}_{3} \mathrm{P}(0001)$ (diamonds), $\mathrm{Ni}_{3} \mathrm{P}_{2}(0001)$ (triangles), $\mathrm{Ni}_{4} \mathrm{P}_{3}(0001)$ (circles). The structures corresponding to each data point are presented in Figure S9.

a consequence of the relatively small shift in the $d$-band centers $(0.1 \mathrm{eV})$ for $\mathrm{Ni}_{x} \mathrm{P}_{y}$ compared to up to $0.5 \mathrm{eV}$ for $\mathrm{Pd}_{x} \mathrm{~S}$, which measures the extent of electronic poisoning. This can be better understood by plotting the adsorption energy of $\mathrm{C}_{2} \mathrm{H}_{2}$ and $\mathrm{C}_{2} \mathrm{H}_{4}$ as a function of the methyl group adsorption (Figure 6 and Figure S9), following the approach proposed by Nørskov and coworkers. ${ }^{[20,35]}$ By applying this model, we can observe that the theoretical points for $\mathrm{Ni}_{2} \mathrm{P}$ and $\mathrm{Ni}_{5} \mathrm{P}_{4}$ lie on the same line with $\mathrm{Ni}$, and the ratio of the slope of the trend lines is identical to that reported, which points to the impossibility of this system to break linear scaling relations. In fact, phosphorus enhances the reactant and product adsorption/desorption to/from the surface by forming $\mathrm{P}-\mathrm{CH}-\mathrm{CH}-\mathrm{P}$ and $\mathrm{P}-\mathrm{CH}_{2}-\mathrm{CH}_{2}-\mathrm{P}$ complexes, which increases the difficulty of the intermediate alkene to detach. Therefore, $\mathrm{C}_{2} \mathrm{H}_{2}$ and $\mathrm{C}_{2} \mathrm{H}_{4}$ adsorptions almost do not vary upon including phosphorus, but they even get more exothermic when the binding occurs via a P-containing site (points labelled as 1 in Figure 6). The above description sets the limits for the use of $p$-block dopants in alkyne hydrogenation. In particular, it shows that the establishment of a general doping strategy requires detailed investigation of the electronic structure of possible new materials.

\section{Conclusions}

The potential of phosphorus to modify the properties of nickel catalysts for alkyne semi-hydrogenation by using nickel phosphides has been explored. Two single phases (i.e., $\mathrm{Ni}_{2} \mathrm{P}$ and $\mathrm{Ni}_{5} \mathrm{P}_{4}$ ) were prepared with different nickel to phosphorus ratios and the properties of the ensembles in the most stable surface terminations were identified, revealing the presence of spatially isolated nickel trimers in all cases. Continuous-flow semi-hydrogenation of 1-hexyne and 2-methyl-3-butyn-2-ol over the catalysts evidenced the higher activity and selectivity of these trimers over unmodified nickel. Depending on the substrate functionality different activity profiles and selectivity patterns are displayed on the phosphides. Comprehensive theoretical analyses including assessment of the adsorption energies and the reaction profiles over the $\mathrm{Ni}_{3}$ ensembles rationalize that the hydroxyl group in the alkynol molecules facilitates each reaction step. While this enhances the activity, the higher desorption barrier compromises the selectivity. Although the modification with phosphorus defines trimeric ensembles and imparts a bifunctional mechanism, it is demonstrated that the electronic properties of the surface are not sufficiently modulated in the range of $\mathrm{Ni} / \mathrm{P}$ ratios investigated leading to lower rate and selectivity levels than encountered over palladium sulfide. Overall, this highlights the fundamental importance of balancing the electronic effects to reach optimal alkyne semi-hydrogenation performance.

\section{Experimental Section}

Materials: $\mathrm{Ni}_{5} \mathrm{P}_{4}$ was synthesized by mixing nickel powder (Sigma Aldrich, 99\%) and red phosphorus powder (Sigma Aldrich, 99\%) in a mortar with a $\mathrm{P} / \mathrm{Ni}$ molar ratio of 2 , and heating the resulting mixture under a nitrogen atmosphere at $773 \mathrm{~K}$, respectively. $\mathrm{Ni}_{2} \mathrm{P}$ was synthesized using the method outlined by Guan et al. ${ }^{[30]}$ with nickel chloride hexahydrate and sodium hypophosphite precursors and a $\mathrm{P} /$ $\mathrm{Ni}$ ratio of 5 . The reference $60 \mathrm{wt} . \% \mathrm{Ni} / \mathrm{SiO}_{2}-\mathrm{Al}_{2} \mathrm{O}_{3}$ (Alfa Aesar, ref: 7440-02-0) catalyst was used as received. Powder X-ray diffraction (XRD) was carried out using a PANalytical X'Pert PRO-MPD diffractometer with $\mathrm{Cu}-\mathrm{K} \alpha$ radiation $(\lambda=0.154 \mathrm{~nm})$. Data was recorded in the $10-70^{\circ} 2 \theta$ range with an angular step size of $0.033^{\circ}$ and a counting time of $8 \mathrm{~s}$ per step. Solid-state ${ }^{31} \mathrm{P}$ magic angle spinning nuclear magnetic resonance ( ${ }^{31} \mathrm{P}$ MAS-NMR) spectroscopy was conducted by a Bruker Advance III HD spectrometer equipped with a 9.4 T magnet (Larmor frequency $f_{\mathrm{L}}=400.13 \mathrm{MHz}$ ). The spectra were recorded by a $2.5 \mathrm{~mm}$ double resonance MAS probe at a spinning speed of $10 \mathrm{kHz}$. $\mathrm{X}$-ray fluorescence spectroscopy (XRF) was used to quantify the Ni and $\mathrm{P}$ contents by using an Orbis Micro instrument equipped with an $\mathrm{Rh}$ source operated at $35 \mathrm{kV}$ and $500 \mathrm{~mA}$. Nitrogen isotherms were obtained at $77 \mathrm{~K}$ using a Micromeritics Tristar instrument, after evacuation of the samples at $473 \mathrm{~K}$ for $3 \mathrm{~h}$.

Catalytic tests: Continuous-flow hydrogenations of 2-methyl-3butyn-2-ol (Sigma Aldrich, 98\%) and 1-hexyne (Acros Organics, $98 \%)$ were carried out in a fully-automated flooded-bed microreactor (ThalesNano $\mathrm{H}$-Cube Pro $^{\mathrm{TM}}$ ), in which molecular hydrogen (produced in situ via water electrolysis) and the liquid feed (introduced by an HPLC pump, Knauer) flow concurrently upward through the catalyst bed. Note that all catalysts were sieved in the particle size range $0.2-0.4 \mathrm{~mm}$ prior to the testing. The reaction products were analyzed offline using a gas chromatograph (HP6890) equipped with a HP-5 capillary column and a flame ionization detector. The conversion $(X)$ of the reactant, which ranges from 5 to $100 \%$ as shown in Figure S5, was determined as the amount of reacted alkyne divided by the amount of alkyne at the reactor inlet; the selectivity $(S)$ to a given product was quantified as the amount of that compound divided by the total amount of reacted alkyne.

Computational details: Density Functional Theory (DFT) calculations were performed using the VASP code. ${ }^{[36,37]}$ The functional of choice was Pedrew-Burke-Ernzenhof (PBE). ${ }^{[38]}$ The inner electrons were replaced by projected-augmented wave (PAW) ${ }^{[39]}$ pseudopotentials with a kinetic cutoff energy of $600 \mathrm{eV}$ for bulk optimizations. The $\Gamma$-centered $k$-point grids were sampled according to the Monkhorst-Pack (MP) ${ }^{[40]}$ scheme and was denser than $0.3 \AA^{-1}$ (Table S1). In case of Nickel, spin polarization is considered. For 
$\mathrm{Ni}_{x} \mathrm{P}_{y}$ systems, spin and non-spin polarization calculations had been compared and the results showed that there is no magnetization in $\mathrm{Ni}_{x} \mathrm{P}_{y}$ systems, thus the same structures were simulated without considering spin polarization. The calculated lattice parameters agree well with experiment and previous DFT results (Table S1). In the slab calculations, the cutoff energy was $450 \mathrm{eV}, \Gamma$-centered $k$ point samplings were also denser than $0.3 \AA^{-1}$. Vacuum length for all of the slabs was $15 \AA$ and half of the layers were fixed. DFT-D2 method developed by Grimme et al. ${ }^{[41,42]}$ is used for the van der Waals interaction with the $C_{6}$ parameters developed in our group. ${ }^{[43,44]}$ Gas-phase molecules were relaxed in a box $20 \times 20 \times$ $20 \AA^{3}$. Segregation and islanding calculations ${ }^{[45]}$ for $\mathrm{Ni}_{2} \mathrm{P}$ and $\mathrm{Ni}_{5} \mathrm{P}_{4}$ were performed by switching $\mathrm{Ni}$ and $\mathrm{P}$ atoms from the surface to bulk for segregation calculations, and on the surface for islanding calculations. Acetylene is taken as surrogate in the calculations for three main reasons: (i) the adsorption is dominated by the alkyne moiety, meaning that the chain only binds to the surface via van der Waals forces; (ii) most of our/previous calculations have been done for acetylene and thus it is easier to analyze the role of phosphorus in the catalysts with respect to other modifiers; and (iii) the number of configurations in the complex $\mathrm{Ni}_{x} \mathrm{P}_{y}$ surfaces grows exponentially when compared to the pure metal in the combined search of many adsorption sites and organic fragment configurations, which are difficult to compile in a simple form. The isomerization reaction was investigated for 1-hexyne. Climbing Image Nudged Elastic Band (CI-NEB) approach ${ }^{[4,47]}$ and the improved dimer algorithms ${ }^{[48]}$ were employed to locate the transition states, which were further verified by their single imaginary frequency character. Solvation (toluene) contributions to the reaction network have also been considered via the MGCM method. ${ }^{[49,50]}$ All structures in the present study can be retrieved from ioChem-BD. ${ }^{[51,52]}$

\section{Acknowledgements}

Financial support from ETH Zurich, and MINECO (grant number CTQ2015-68770-R). The Barcelona Supercomputing Centre (BSCRES) is thanked for access to its facilities. Dr. René Verel is acknowledged for conducting NMR analyses and for discussions.

\section{Conflict of Interest}

The authors declare no conflict of interest.

Keywords: alkyne semi-hydrogenation • DFT calculations ensemble design $\cdot$ nickel phosphide $\cdot$ structure sensitivity

[1] R. A. Sheldon, Green Chem. 2014, 16, 950-963.

[2] R. A. Sheldon, Chem. Soc. Rev. 2012, 41, 1437-1451.

[3] H. Lindlar, Helv. Chim. Acta 1952, 35, 446-450.

[4] W. Bonrath, J. Medlock, J. Schütz, B. Wüstenberg, T. Netscher, in Hydrogenation, InTech, 2012.

[5] M. García-Mota, J. Gómez-Díaz, G. Novell-Leruth, C. Vargas-Fuentes, L. Bellarosa, B. Bridier, J. Pérez-Ramírez, N. López, Theor. Chem. Acc. 2011, 128, 663-673.

[6] G. Vilé, D. Albani, N. Almora-Barrios, N. López, J. Pérez-Ramírez, ChemCatChem 2016, 8, 21-33.

[7] M. García-Mota, B. Bridier, J. Pérez-Ramírez, N. López, J. Catal. 2010, 273, 92-102.
[8] A. J. McCue, J. A. Anderson, Front. Chem. Sci. Eng. 2015, 9, 142-153.

[9] B. Bridier, N. López, J. Pérez-Ramírez, J. Catal. 2010, 269, 80-92.

[10] D. L. Trimm, I. O. Y. Liu, N. W. Cant, Appl. Catal. A 2010, 374, 58-64.

[11] B. Bridier, N. López, J. Pérez-Ramírez, Dalton Trans. 2010, 39, 8412-8419.

[12] D. Teschner, J. Borsodi, A. Wootsch, Z. Révay, M. Hävecker, A. KnopGericke, S. D. Jackson, R. Schlögl, Science 2008, 320, 86-89.

[13] D. Albani, M. Shahrokhi, Z. Chen, S. Mitchell, R. Hauert, N. López, J. Pérez-Ramírez, Nat. Commun. 2018, 9, 2634.

[14] A. J. McCue, A. Guerrero-Ruiz, C. Ramirez-Barria, I. Rodríguez-Ramos, J. A. Anderson, J. Catal. 2017, 355, 40-52.

[15] S. T. Oyama, T. Gott, H. Zhao, Y.-K. Lee, Catal. Today 2009, 143, 94-107.

[16] R. Prins, M. E. Bussell, Catal. Lett. 2012, 142, 1413-1436.

[17] C.-C. Hou, Q. Li, C.-J. Wang, C.-Y. Peng, Q.-Q. Chen, H.-F. Ye, W.-F. Fu, C.M. Che, N. López, Y. Chen, Energy Environ. Sci. 2017, 10, 1770-1776.

[18] E. J. Popczun, J. R. McKone, C. G. Read, A. J. Biacchi, A. M. Wiltrout, N. S. Lewis, R. E. Schaak, J. Am. Chem. Soc. 2013, 135, 9267-9270.

[19] S. Carenco, D. Portehault, C. Boissière, N. Mézailles, C. Sanchez, Chem. Rev. 2013, 113, 7981-8065.

[20] F. Studt, F. Abild-Pedersen, T. Bligaard, R. Z. Sørensen, C. H. Christensen, J. K. Nørskov, Science 2008, 320, 1320-1322.

[21] A. Borodziński, G. C. Bond, Catal. Rev. 2006, 48, 91-144.

[22] S. Carenco, A. Leyva-Pérez, P. Concepcion, C. Boissière, N. Mézailles, C. Sanchez, A. Corma, Nano Today 2012, 7, 21-28.

[23] Y. Chen, C. Li, J. Zhou, S. Zhang, D. Rao, S. He, M. Wei, D. G. Evans, X. Duan, ACS Catal. 2015, 5, 5756-5765.

[24] Y. Liu, A. J. McCue, C. Miao, J. Feng, D. Li, J. A. Anderson, J. Catal. 2018 364, 406-414.

[25] A. Renken, L. Kiwi-Minsker, in Advances in Catalysis, Vol. 53 (Eds.: B. C Gates, H. Knözinger), Academic Press, 2010, pp. 47-122.

[26] K. S. Elvira, X. C. i Solvas, R. C. Wootton, A. J. deMello, Nat. Chem. 2013 5, 905.

[27] D. Albani, G. Vilé, M. A. Beltran Toro, R. Kaufmann, S. Mitchell, J. PérezRamírez, React. Chem. Eng. 2016, 1, 454-462.

[28] M. N. Kashid, L. Kiwi-Minsker, Ind. Eng. Chem. Res. 2009, 48, 6465-6485.

[29] R. García-Muelas, Q. Li, N. López, J. Phys. Chem. B 2018, 122, 672-678.

[30] Q. Guan, W. Li, M. Zhang, K. Tao, J. Catal. 2009, 263, 1-3.

[31] C. Stinner, Z. Tang, M. Haouas, T. Weber, R. Prins, J. Catal. 2002, 208, 456-466.

[32] E. Bekaert, J. Bernardi, S. Boyanov, L. Moncounduit, M.-L. Doublet, M. Ménétrier, J. Phys. Chem. 2008, 112, 20481.

[33] X. Feng, M. Tang, S. O'Neill, Y.-Y. Hu, J. Mater. Chem. A 2018 doi:10.1039/C8TA05433 A.

[34] Q. Li, X. Hu, Phys. Rev. B 2006, 74, 035414.

[35] Y. Segura, N. López, J. Pérez-Ramírez, J. Catal. 2007, 247, 383-386.

[36] G. Kresse, J. Furthmüller, Phys. Rev. B 1996, 54, 11169-11186.

[37] G. Kresse, J. Furthmüller, Comput. Mater. Sci. 1996, 6, 15-50.

[38] J. P. Perdew, K. Burke, M. Ernzerhof, Phys. Rev. Lett. 1996, 77, 3865-3868.

[39] P. E. Blöchl, Phys. Rev. B 1994, 50, 17953-17979.

[40] H. J. Monkhorst, J. D. Pack, Phys. Rev. B 1976, 13, 5188-5192.

[41] S. Grimme, J. Comput. Chem. 2006, 27, 1787-1799.

[42] T. Bučko, J. Hafner, S. Lebègue, J. G. Ángyán, J. Phys. Chem. A 2010, 114, 11814-11824.

[43] N. Almora-Barrios, G. Carchini, P. Błoński, N. López, J. Chem. Theory Comput. 2014, 10, 5002-5009.

[44] P. Błoński, N. López, J. Phys. Chem. C 2012, 116, 15484-15492.

[45] N. López, C. Vargas-Fuentes, Chem. Commun. 2012, 48, 1379-1391.

[46] G. Henkelman, B. P. Uberuaga, H. Jónsson, J. Chem. Phys. 2000, 113, 9901-9904.

[47] G. Henkelman, H. Jónsson, J. Chem. Phys. 2000, 113, 9978-9985.

[48] A. Heyden, A. T. Bell, F. J. Keil, J. Chem. Phys. 2005, 123, 224101.

[49] M. Garcia-Ratés, N. López, J. Chem. Theory Comput. 2016, 12, 1331-1341.

[50] M. Garcia-Ratés, R. García-Muelas, N. López, J. Phys. Chem. C 2017, 121, 13803-13809.

[51] M. Álvarez-Moreno, C. de Graaf, N. López, F. Maseras, J. M. Poblet, C. Bo, J. Chem. Inf. Model. 2015, 55, 95-103.

[52] K. Karajovic, Q. Li, N. López, Database for Ensemble design in nickel phosphide catalysts for alkyne semi-hydrogenation. DOI: 10.19061/ iochem-bd-1-94

Manuscript received: September 2, 2018

Version of record online: November 20, 2018 